\title{
HUBUNGAN PERAN KELUARGA TERHADAP KEAKTIFAN MENGIKUTI SENAM LANSIA
}

\author{
Ayu Anggraeni, Yanti Sutriyanti, Surani Warsito \\ Politeknik Kesehatan Kementerian Kesehatan Bengkulu, Jurusan Keperawatan, \\ Jalan Indragiri Nomor 3 Padang Harapan Bengkulu \\ jmkbengkulu@gmail.com
}

\begin{abstract}
The role of family at affective, socialization, health care affects the elderly in increasing active in efforts improved health in physical, mental, social and efforts to increase life expectancy that is free from distractions.Risert purpose to determine the role of the Family Relationships Following Gymnastics Against Elderly Motivation In Work Area Health Center Build Jaya in 2014.This study used a cross sectional design, engineering to get samples using cluster random sampling the samples of 54 elderly health centers in the Work Area Jaya Build 2014. Processed data using univariate and bivariate using Chi Square test.Most of respondents (75.9\%) female, the majority of respondents $(53.7 \%)$ had a poor family role and most of the respondents $(61.1 \%)$ active follow gymnastics elderly. There is a relationship between the role of the family with the liveliness of the elderly with a $p=0.001 \mathrm{CI}: 95 \%$. The role of family it will be very influential to give a support on the increased activity of the elderly so that physical functioning, mental, social get a good care anyway.
\end{abstract}

Keywords: Role of Family, active and elderly

Abstrak: Peran keluarga pada fungsi afektif, sosialisasi, dan perawatan kesehatan berpengaruh terhadap lansia dalam meningkatkan keaktifan yang merupakan salah satu upaya peningkatan kesehatan baik fisik, mental, sosial dan peningkatan usia harapan hidup yang bebas dari gangguan. Tujuan penelitian ini untuk mengetahui Hubungan Peran Keluarga Terhadap Keaktifan Mengikuti Senam Lansia Di Wilayah Kerja Puskesmas Bangun Jaya Tahun 2014. Penelitian ini menggunakan desain Cross Sectional, dengan tehnik pengambilan sampel secara Cluster Random Sampling Sampel sebanyak 54 lansia di Wilayah Kerja Puskesmas Bangun Jaya. Data diolah secara univariat dan bivariat dengan menggunakan uji Chi Square. Hampir seluruh (75.9\%) lansia berjenis kelamin perempuan, dan sebagian besar (53,7\%) lansia mempunyai peran keluarga kurang baik serta sebagian besar $(61,1 \%)$ lansia aktif mengikuti senam. Ada hubungan antara peran keluarga dengan keaktifan lansia dengan nilai $p=0,001 \mathrm{CI}: 95 \%$. Peran keluarga dibutuhkan untuk memberikan dukungan terhadap lansia dalam meningkatkan keaktifan senam lansia sehingga fungsi fisik, mental, dan sosial lansia terpelihara dengan baik.

Kata kunci : Peran Keluarga, Keaktifan, Lansia

WHO memprediksikan bahwa Indonesia akan mengalami peningkatan jumlah usia lanjut sebesar 28,8 juta orang $(11,34 \%)$ pada tahun 2020. Lansia mengalami proses penuaan secara alamiah yang dapat menimbulkan masalah fisik, mental, sosial, ekonomi, dan psikologis. Perubahan tersebut pada umumnya mengarah kepada kemunduran kesehatan fisik dan psikis yang akhirnya akan berpengaruh juga pada aktivitas ekonomi, sosial dan secara umum akan berpengaruh pada kehidupan sehari-hari. Beberapa hal yang perlu diperhatikan agar tetap sehat di usia lanjut salah satunya dengan memperhatikan faktor olahraga senam (Nugroho, 2000). Manfaat dari senam lansia yaitu mampu melatih tubuh untuk tetap bugar, mendorong jantung tetap bekerja optimal, serta meningkatkan kebugaran.

Blewitt (2007) mengatakan peran keluarga akan mempengaruhi kesehatan lansia. Untuk memelihara kesehatan dari lansia itu sendiri diperlukan dukungan dari keluarga dalam meningkatkan pemeliharaan kesehatan lansia. Salah satu dukungan keluarga dalam pemeliharaan kesehatan lansia dengan memberikan fasilitas dan dorongan terhadap lansia untuk 
mengikuti suatu aktivitas/kegiatan berupa senam lansia.

Peran keluarga untuk mengikuti kegiatan senam lansia di puskesmas Bangun Jaya diperlukan, mengingat jumlah lansia dipuskesmas Bangun Jaya termasuk jumlah lansia yang banyak di kabupaten Rejang Lebong dengan jumlah 790 jiwa. Puskesmas Bangun Jaya mempunyai 5 kasus penyakit degeneratif terbanyak meliputi penyakit rematik, hipertensi, gastritis, dan DM.

Puskesmas Bangun Jaya mempunyai 9 wilayah kerja posyandu, dimana posyandu yang masih aktif melaksanakan senam lansia hanya 4 posyandu dengan kehadiran keseluruhan lansia yang mengikuti senam $40 \%$. Wawancara dengan beberapa lansia mengenai kegiatan senam yang dilaksanakan mengatakan bahwa ketidakhadiran mengikuti senam lansia dikarenakan tidak mendapat izin dari keluarganya untuk keluar rumah.

Tujuan penelitian ini untuk mengetahui Hubungan Peran Keluarga Terhadap Keaktifan Mengikuti Senam Lansia Di Wilayah Kerja Puskesmas Bangun Jaya Tahun 2014.

\section{BAHAN DAN CARA KERJA}

Penelitian ini deskriptif analitik mengunakan desain potong lintang yang bertujuan untuk mengetahui hubungan peran keluarga terhadap keaktifan lansia mengikuti senam lansia di wilayah kerja Puskesmas Bangun Jaya. Observasi, atau pengukuran dengan menggabungkan variabel sebab dan akibat yang terjadi pada obyek penelitian dan diukur pada suatu saat (point time approach) (Notoatmodjo, 2010).

Populasi dari penelitian ini adalah seluruh lansia yang tinggal di bawah wilayah kerja Puskesmas Bangun Jaya yang masih aktif melaksanakan kegiatan senam lansia di 4 posyandu wilayah kerja Puskesmas Bangun Jaya. Jumlah populasi sebanyak 431 orang lansia. Sampel diambil di 4 desa wilayah kerja Puskesmas Bangun Jaya Kabupaten Rejang Lebong sebanyak 54 orang. Tehnik pengambilan sampel secara cluster sampling.

\section{HASIL}

\section{Analisa Univariat}

Tabel 1 dan 2 menunjukkan hampir seluruh responden $(75.9 \%)$ berjenis kelamin perempuan dengan umur rata-rata responden yaitu 51 tahun, sebagian besar dari responden $(53,7 \%)$ mempunyai peran keluarga kurang baik dan sebagian besar dari responden $(61,1 \%)$ aktif mengikuti senam lansia

\begin{tabular}{|c|c|c|}
\hline Karakteristik & $\begin{array}{c}\text { Frekuensi } \\
(\mathrm{N}=54)\end{array}$ & $\begin{array}{c}\text { Persentase } \\
(\mathbf{1 0 0 \%})\end{array}$ \\
\hline \multicolumn{3}{|l|}{ Jenis Kelamin } \\
\hline Laki-laki & 13 & 24,1 \\
\hline Perempuan & 41 & 75,9 \\
\hline \multicolumn{3}{|l|}{ Peran keluarga } \\
\hline Baik & 25 & 46,3 \\
\hline Kurang Baik & 29 & 53,7 \\
\hline \multicolumn{3}{|l|}{ Keaktifan senam } \\
\hline Aktif & 33 & 61,1 \\
\hline Tidak aktif & 21 & 38,9 \\
\hline
\end{tabular}

Tabel 2 Karakteristik lansia berdasarkan Umur Lansia

\begin{tabular}{cccc}
\hline Karakteristik & Mean & Median & Modus \\
\hline Umur & 50.78 & 50 & 48 \\
\hline
\end{tabular}

\section{Analisa Bivariat}

Tabel 4 Hubungan Peran Keluarga dengan Keaktifan Mengikuti Senam Lansia

\begin{tabular}{|c|c|c|c|c|c|c|c|}
\hline \multirow[t]{3}{*}{ Peran keluarga } & \multicolumn{4}{|c|}{ Keaktifan senam } & \multicolumn{2}{|c|}{ Total } & \multirow{3}{*}{$\mathbf{p}$} \\
\hline & \multicolumn{2}{|c|}{ Aktif } & \multicolumn{2}{|c|}{ Tidak aktif } & \multirow{2}{*}{$\mathbf{n}$} & \multirow{2}{*}{$\%$} & \\
\hline & $\mathrm{n}$ & $\%$ & $\mathbf{n}$ & $\%$ & & & \\
\hline Baik & 21 & 84,0 & 4 & 16,0 & 25 & 100 & 0,001 \\
\hline Kurang Baik & 12 & 41,4 & 17 & 58,0 & 29 & 100 & \\
\hline
\end{tabular}

Tabel 4 menunjukkan bahwa dari peran keluarga yang baik lansia yang mengikuti senam dengan aktif (84\%). Hasil analisis didapatkan $(\mathrm{p}=0,001<\alpha 0,05)$ maka ada hubungan antara peran keluarga dengan keaktifan mengikuti senam lansia di wilayah kerja Puskesmas Bangun Jaya Tahun 2014.

\section{PEMBAHASAN}

\section{Peran Keluarga}

Sebagian besar $(53,7 \%)$ keluarga lansia mempunyai peran keluarga yang kurang baik. Kuntjoro (2002) mengatakan bahwa bagi lansia agar tetap beraktivitas maka harus adanya dukungan keluarga. Penelitian Azizah (2011) 
menyebutkan bahwa adanya hubungan keberhasilan senam dengan dukungan kelurga karena keluarga merupakan salah satu unsur penting dalam membangun kesadaran lansia akan pentingnya senam lansia dalam hal ini sebuah peran keluarga sangat dibutuhkan sebagai motivasi, pemahaman manfaat dan pentingnya senam lansia bagi lansia.

Teori yang dikemukakan oleh Yohanes (2013) bahwa peran keluarga menggambarkan seperangkat perilaku interpersonal, sifat, kegiatan yang berhubungan dengan individu dan juga sebagai perilaku yang diharapkan dari seseorang dalam situasi tertentu. Teori Setiadi (2013) dikatakan bahwa dimana keluarga juga merupakan basis sentral bagi pembentukan dalam mempersiapkan anggota keluarga berhubungan dengan orang lain dengan memperhatikan komponen yang diperlukan yaitu, menerima, menghormati dan mendukung antar anggota keluarga, menaruh perhatian, cinta kasih, untuk hidup bersosialisasi, serta untuk mempertahankan keadaan kesehatan anggota keluarga.

Peneliti menyimpulkan bahwa peran keluarga yang kurang baik bisa mempengaruhi perilaku anggota keluarga (lansia) dalam bersosialisasi di lingkungan sekitarnya, seperti lebih cenderung pasif atau berdiam diri saja dikarenakan kurangnya keluarga dalam menaruh perhatian untuk saling memotivasi, saling asuh, saling menghormati seperti selayaknya peran keluarga yang dijelaskan.

\section{Keaktifan Mengikuti Senam Lansia}

Sebagian besar $(61,1 \%)$ lansia aktif mengikuti senam. Teori yang dikemukakan oleh Sardiman (2001) bahwa keaktifan adalah ke-giatan yang bersifat fisik maupun mental, yaitu berbuat dan berfikir sebagai suatu rangkaian yang tidak dapat dipisahkan, dimana keaktifan dalam kegiatan tidak lain adalah untuk meng-konstruksi pengetahuan (proses menua) lansia sendiri. Menurut Ilham (2011) bahwa ada beberapa faktor yang mempengaruhi keaktifan itu sendiri salah satunya yaitu memberikan motivasi atau menarik perhatian individu, sehingga lansia berperan aktif dalam kegiatan dan memberikan stimulus (masalah, topik, dan konsep menua yang akan dipelajari).

Hawari (2001) menyebutkan bahwa dukungan dari keluarga (suami, istri, anak, cucu) sangat diperlukan lansia untuk menyokong rasa percaya diri dan perasaan dapat menguasai lingkungan. Penelitian ini sejalan dengan penelitian yang dilakukan oleh Indah (2010) nampak bahwa adanya hubungan yang signifikan antara dukungan keluarga dengan keaktifan mengikuti posyandu lansia dengan bentuk peran keluarga misalnya dalam mengingatkan jadwal dilakukannya kegiatan posyandu lansia, keluarga mengantar ke posyandu lansia, keluarga selalu menasehati lansia untuk aktif dalam kegiatan.

Lansia justru harus tetap melakukan aktivitas-aktivitas yang berguna bagi kehidupannya dalam menjaga kesehatan baik fisik maupun kejiwaannya. Lansia tidak boleh diam atau pasif dalam beraktivitas dan selalu dilayani oleh orang lain. Hal ini justru akan mendatangkan berbagai penyakit dan penderitaan, sehingga bisa menyebabkan para lansia tersebut cepat terpapar penyakit bahkan meninggal dunia.

\section{Hubungan Peran Keluarga Terhadap Keaktifan Mengikuti Senam Lansia}

Hasil analisis bivariat menunjukkan bahwa ada hubungan antara peran keluarga dengan keaktifan mengikuti senam lansia di wilayah kerja Puskesmas Bangun Jaya Tahun 2014. Penelitian ini sejalan dengan penelitian yang dilakukan oleh Indah (2010) dan Novaria (2012) yang menyebutkan bahwa ada hubungan antara dukungan keluarga dengan tingkat keaktifan lansia dalam mengikuti senam lansia . Bentuk peran keluarga yang diberikan keluarga misalnya dalam mengingatkan jadwal dilakukannya kegiatan posyandu lansia, dan kegiatan senam bagi lansia, keluarga mengantar ke posyandu lansia, keluarga selalu menasehati lansia untuk aktif dalam mengikuti kegiatan senam.

Penelitian ini menunjukkan bahwa sesuai dengan teori yang menyebutkan meskipun setelah adanya suatu dukungan keluarga tidak berarti memasuki masa lansia tinggal duduk, tenang, dan berdiam diri saja. Lansia justru harus tetap melakukan aktivitas-aktivitas yang berguna bagi kehidupannya dalam menjaga kesehatan baik fisik maupun kejiwaannya dan 
mengetahui manfaat dari senam lansia itu sendiri. Lansia tidak boleh diam atau pasif dalam beraktivitas dan selalu dilayani oleh orang lain. Hal ini justru akan mendatangkan berbagai penyakit dan penderitaan, sehingga bisa menyebabkan para lansia tersebut cepat terpapar penyakit bahkan meninggal dunia.

\section{KESIMPULAN}

Hasil Penelitian disimpulkan bahwa hampir seluruh lansia berjenis kelamin perempuan, de-ngan umur rerata 51 tahun. Hampir sebagian dari keluarga lansia mempunyai peran keluarga baik terhadap keaktifan lansia. Sebagian besar dari lansia aktif mengikuti kegiatan senam lansia. Jadi, ada hubungan antara peran keluarga dengan keaktifan mengikuti senam lansia.

Bagi lansia dan keluarga, keluarga dapat mempertahankan dan meningkatkan dalam memberikan motivasi terhadap lansia untuk aktif dalam mengikuti kegiatan senam lansia, karena manfaat senam bagi lansia dapat

\section{DAFTAR RUJUKAN}

Hawari. 2001. Manajemen Stress, Cemas dan Depresi. Jakarta:FKUI

Indah. 2010. Hubungan Dukungan Keluarga Dengan Keaktifan Lansia Mengikuti Kegiatan Di Posyandu Lansia Desa Gonilan Kartasura. Skripsi. UMS

Kuntjoro. 2002. Masalah Kesehatan Jiwa Lansia. Diakses tanggal 13 Mei 2014. http://www.e-psikologi.co.id

Notoatmodjo. 2010. Metodologi Penelitian Kesehatan. Jakarta : Rineka Cipta

Novaria,Vivin. 2012. Hubungan Dukungan Keluarga Tentang Senam Lansia Dengan Keaktifan menurunkan angka kesakitan lansia sehingga lansia dapat mempertahankan kesehatannya. Penelitian ini dapat dilanjutkan dengan meneliti faktor lainnya yang dapt mempengaruhi keaktifan lansia seperti faktor internal lansia yaitu kebutuhan, motivasi, psikologis, dan faktor eksternal lansia seperti dukungan keluarga, dukungan rekan sesama lansia, penggalangan berbagai program yang diperuntukan untuk lansia seperti perawatan keluarga, dan lain sebagainya yang dapat meningkatkan keaktifan lansia untuk mengikuti kegiatan olahraga sehingga lansia dapat memelihara dan mempertahankan kesehatannya. Bagi Puskesmas, program yang dilaksanakan puskesmas Bangun Jaya hendaknya dapat meningkatkan peran keluarga lansia dalam memberikan dukungan atau motivasinya mengoptimal keaktifan lansia mengikuti program senam lansia, sehingga diperlukan pertemuan khusus terhadap keluarga lansia agar keluarga lansia menyadari akan perannya terhadap lansia untuk memelihara kesehatannya.

Mengikuti Senam Di Posyandu Desa Pabelan. Skripsi. UMS

Nugroho, Wahyudi. 2000. Keperawatan Gerontik. Jakarta : EGC

Setiadi. 2013. Konsep dan Proses Keperawatan Keluarga. Yogyakarta: Graha Ilmu.

Susenas. 2009. Undang-undang Republik Indonesia nomor 23 tahun 1992 tentang kesehatan.

WHO. 2012. Profil Data Kesehatan Indonesia.Jakarta : WHO.

Yohanes. 2013. Asuhan Keperawatan Keluarga Konsep dan Praktik. Yogyakarta : Nuha Medika. 